\title{
HUBUNGAN STATUS GIZI DENGAN USIA MENARCHE PADA SISWI SMP NEGERI 1 KUNTO DARUSSALAM TAHUN 2016
}

\author{
Relationship Nutritional Status With Menarche Age Students of \\ Junior High School of Negeri 1 Kunto Darussalam Year 2016
}

\author{
Refni Oktaviani ${ }^{1}$, Nanda Novziransyah ${ }^{2}$ \\ ${ }^{1}$ Fakultas Kedokteran Universitas Islam Sumatera Utara, Jl. STM No. 77 Medan \\ Jl. Sisingamangaraja No.2A Medan, Email : refnioktaviani17@gmail.com \\ ${ }^{2}$ Dosen Fakultas Kedokteran Universitas Islam Sumatera Utara, Jl. STM No. 77 Medan \\ Jl. Sisingamangaraja No.2A Medan, Email : ndanovzi@yahoo.com
}

\begin{abstract}
Abstrak
Menarche adalah haid pertama yang dialami oleh setiap remaja yang akan memasuki masa pubertas. Usia saat seorang anak perempuan mulai mendapat menstruasi sangat bervariasi. Beberapa penelitian terbaru menunjukkan bahwa usia menarche pada masa remaja mengalami penurunan beberapa tahun terakhir. Menurunnya usia menarhe disebabkan oleh beberapa faktor salah satunya adalah status gizi. Jenis penelitian yang digunakan yaitu observasi analitik yang bertujuan untuk mengetahui hubungan status gizi dengan usia menarche pada siswi SMP Negeri 1 Kunto Darussalam Tahun 2016 dengan pendekatan cross sectional. Populasi dalam penelitian ini adalah seluruh siswi SMP Negeri 1 Kunto Darussalam yang berjumlah 210 orang. Metode consecutive sampling digunakan untuk mengambil sampel dengan jumlah sampel keseluruhan 68 orang. Data yang dikumpulkan terdiri atas data primer dan data sekunder. Data primer dikumpulkan dengan melakukan pengukuran langsung dan pengisian kuesioner, data sekunder didapatkan dari bagian Tata Usaha Sekolah. Tehnik analisa data yang digunakan adalah tehnik analisis data univariat dan bivariat. Pengujian hipotesis dilakukan pada taraf signifikansi 0.05 atau $95 \%$.

Hasil penelitian di dapatkan rata-rata usia menarche pada siswi SMP Negeri 1 Kunto Darussalam Tahun 2016 adalah 11.66 tahun.Dari hasil penelitian menunjukkan bahwa terdapat perbedaan rata-rata usia menarche antara kelompok status gizi Underweight, Normalweight, Pre-Obesity dan Obesity. Didapatkan bahwa rata-rata usia menarche lebih awal terjadi pada siswi Obesity yaitu 10.25 tahun. Berdasarkan hasil analisa menggunakan Uji Chi-Squaredidapatkan ( $p$-value=0.013), dapat disimpulkan bahwa terdapat hubungan antara status gizi dengan usia menarche. Dari hasil penelitian disarankan kepada para remaja untuk menjalani gaya hidup dan pola hidup yang sehat, sehingga dapat tercapainya kesehatan reproduksi yang normal.
\end{abstract}

Kata kunci : Menarche, Status Gizi.

\begin{abstract}
Menarche is the first period experienced (menstruation) by every adolescent who will enter puberty. The age when a girl began menstruating are very varied. Several recent studies indicate that the age of menarche in adolescence has decreased in recent years. The decline in the age of menarhe caused by several factors, one of them is nutritional status. This type of research is used observational analytic to determine the relationship of nutritional status and the age of menarche in junior high school 1 Kunto Darussalam 2016 with cross sectional approach. The population in this research were all students of Junior high school 1 Kunto Darussalam totaling 210 people. Consecutive sampling method is used to take a sample with a sample of 68 people overall. The collected data include consist of primary data and secondary data. Primary data was collected by direct measurement and questionnaires, secondary data obtained from the Administration School. Analysis techniques data used are analysis techniques data univariate and bivariate. Hypothesis testing was doing at the level of significance of 0.05 or $95 \%$.

The results of this research shown the average age of menarche in junior high school 1 Kunto Darussalam 2016 is 11.66 years. From the results showed that there are differences in the average age of menarche between the nutritional status Underweight, Normalweight, Pre-Obesity and Obesity. It was found that the average age of menarche earlier occurred in student years Obesity is 10.25. Based on the analysis using Chi-Square(p-value $=0.013$ ), it can be concluded that there is relationship between nutritional status and age of menarche. From results of this research suggested to the adolescent to live a life style and a healthy life style, so that it can achieve normal reproductive health.
\end{abstract}

Key words: menarche, nutritional status 


\section{PENDAHULUAN}

Masa remaja merupakan masa transisi dari masa anak-anak kemasa dewasa. Usia remaja, sesuai keputusan WHO/UNFPA adalah 10-19 tahun. Usia ini dibagi dua kelompok usia yakni: (1) antara 10-15 dan antara 15-19 tahun. Usia 10-15 tahun di kenal sebagai masa pertumbuhan cepat (growth spurt). Di sini terjadi serangkaian perubahan menuju kematangan fisik dan seksual (Agria, dkk, 2012).

Dalam tumbuh kembangnya menuju dewasa, berdasarkan kematangan psikososial dan seksual, remaja akan melewati tahapan berikut: (1) Masa remaja awal (Early adolescence) umur 11-13 tahun (2) Masa remaja pertengahan (Midlle adolescence) umur 14-16 tahun (3) Masa remaja lanjut (Late adolescence) umur 17-20 tahun (Noerpramana, 2011).

Seiring dengan usia yang semakin meningkat akan berlaku pubertas, yang merupakan suatu tahap perkembangan yang sangat penting bagi wanita (Aishah, 2011). Pada anak perempuan, tanda pubertas pertama adalah pertumbuhan payudara stadium dua (atau disebut breast bud), berupa penonjolan puting disertai pembesaran daerah areola, yang terjadi pada umur sekitar 8-12 tahun. Haid pertama (menarche) terjadi pada stadium lanjut pubertas dan sangat bervariasi antar individu (Soetjiningsih, 2015).

Menarche merupakan mentruasi yang pertama terjadi, yang merupakan ciri khas kedewasaan seorang wanita sehat dan tidak hamil ${ }^{(5)}$. Secara historis, usia saat permulaan menstruasi menarche secara terus menerus telah berkurang sampai beberapa tahun terakhir (Gant dan Garry, 2011).

Menurut Sanderowitz dan Paxman dalam Sarwono (2011), mencatat bahwa di berbagai masyarakat sekarang ini ada kecenderungan menurunnya usia kematangan seksual seseorang sebagaimana tercermin dalam menurunnya usia menarche (haid pertama).

Menarche terjadi pada rata-rata umur 13 tahun, umur saat menarche maju ratarata 3-4 bulan tiap 10 tahun (berdasarkan penelitian yang diadakan pada tahun
1830-1990, di Norwegia, Perancis, Inggris, Islandia, Jepang, Amerika dan China) (Noerpramana, 2011).

Faktor yang mempengaruhi usia menarche dikalangan anak remaja ialah faktor genetik, etnis, psikologis, lemak tubuh, nutrisi dan aktivitas fisikal. Faktor lingkungan seperti kediaman di kota atau luar kota, pendapatan keluarga, besarnya keluarga, tingkat pendidikan orang tua mempengaruhi perkembangan pubertas pada remaja (Karapanou dan Papadimitriou, 2010).

Status gizi remaja wanita sangat mempengaruhi menarche (Banudi, 2013). Menurunnya usia kematangan seksual ini kiranya terjadi hampir seluruh dunia, sehubungan dengan membaikknya gizi sejak masa kanak-kanak di satu pihak dan meningkatnya informasi melalui media massa atau hubungan antarorang di pihak lain $^{(8)}$. Terjadinya penurunan usia dalam mendapatkan menarche sebagian besar di pengaruhi oleh adanya perbaikan gizi. Tingkat kualitas gizi yang lebih baik pada masyarakat saat ini memicu menstruasi dini (Proverawati dan Siti, 2014).

Di negara maju, perbaikan status gizi mendewasakan fisik anak perempuan lebih dini. Pada selompok ini, rata-rata usia menarche kini telah sampai ketitik 12,8 tahun (Arisman, 2010).

Menurut L. Simkins dalam Sarwono (2011), dinegara-negara maju rata-rata usia menarche menurun 4 bulan setiap 10 tahun dan akan mencapai titik stabil pada usia 12 tahun 9 bulan.

Pada penelitian di Amerika serikat menunjukkan usia menarche rata-rata telah berkurang dari 12,75 tahun menjadi 12,54 tahun dalam waktu 25 tahun. Pada penelitian yang lain dilaporkan bahwa pada usia 11 tahun $28 \%$ dari anak-anak Afrika-Amerika telah menarche dan 13\% dari anak kulit putih Amerika telah menarche. Dan pada usia 12 tahun 68\% anak perempuan Afrika-Amerika dan 35\% anak kulit putih mengalami menarche. Pada penelitian yang sama di Britain, menunjukkan usia rata-rata menarche adalah 12 tahun 11 bulan, dan pada penelitian lain di Netherlands menunjukkan pada tahun 1985 dan 1997, usia pubertas rata-rata telah berkurang 
dari 11 tahun kepada 10,7 tahun (Edward, 2007).

Demikian pula di Indonesia, menurut penelitian yang diadakan di Medan pada siswa Sekolah Dasar (SD) dan Sekolah Menengah Pertama (SMP) Syafiyyatul Amaliah tahun 2011 didapati rata-rata usia menarche yaitu 11,62 tahun (Aishah, 2011).

Usia menarche memiliki implikasi kesehatan yang penting, karena menarche dini berhubungan dengan insidensi kardiovaskular yang lebih tinggi, termasuk kanker terutama kanker payudara. Selain itu, menarche dini berhubungan dengan gejala kecemasan, depresi, hubungan seks prematur dan prilaku kekerasan (Karapanou dan Papadimitriou, 2010).

Berdasarkan keterangan diatas dan juga penelitian-penelitian yang telah dilakukan menunjukkan bahwa telah berlaku penurunan usia menarche secara global di dunia termasuk di Indonesia. Oleh sebab itu penulis tertarik untuk melakukan penelitian bagaimana Hubungan Status Gizi dengan Usia Menarche pada Siswi SMP Negeri 1 Kunto Darussalam tahun 2016.

\section{RUMUSAN MASALAH}

Berdasarkanuraianlatar belakang sebelumnya, maka perumusan masalah yang dapat dikembangkan dalam penelitian ini adalah bagaimana "Hubungan Status Gizi dengan Usia Menarche pada Siswi SMP Negeri 1 Kunto Darussalam Tahun 2016, Riau".

\section{HIPOTESA}

Terdapat hubungan antara status gizi dengan usia menarche pada siswi SMP Negeri 1 Kunto Darussalam Tahun 2016.

\section{TUJUAN PENELITIAN}

Tujuan umum penelitian ini adalah untuk mengetahui hubungan status gizi dengan usia menarche pada siswi SMP Negeri 1 Kunto Darussalam tahun 2016.

Yang menjadi tujuan khusus dalam penelitian ini adalah :

1. Untuk mengetahui usia menarche pada siswi SMP Negeri 1 Kunto Darussalam tahun 2016.
2. Untuk mengetahui status gizi pada siswi SMP Negeri 1 Kunto Darussalam tahun 2016.

\section{MANFAAT PENELITIAN}

Hasil penelitian ini diharapkan dapat memberikan manfaat untuk :

a) Bagi Peneliti

Menambah pengetahuan dan wawasan peneliti tentang peran pentingnya status gizi terhadap usia menarche.

b) Bagi Subjek Penelitian

Menambah pengetahuan remaja putri tentang peranan gizi dalam masa pertumbuhan remaja demi mencapai perkembangan reproduksi yang normal.

c) Bagi Sekolah

Memberikan pengetahuan dan mendorong para guru untuk memberikan informasi kepada siswi tentang pentingnya gizi pada masa pertumbuhan dan memberikan masukan kepada pihak kantin sekolah supaya menyediakan makanan yang berkhasiat dan bergizi seperti sayur-mayur, mengurangkan makanan yang berkolesterol tinggi seperti goreng-gorengan.

d) Bagi masyarakat

Sebagai sumber informasi kesehatan reproduksi tentang sejauh mana status gizi dapat mempengaruhi usia menarche pada wanita.

Bagi Pelayanan Kesehatan
Masyarakat
Memberikan masukan kepada pelayanan kesehatan masyarakat agar melakukan penyuluhan tentang status gizi dan kesehatan reproduksi remaja untuk meningkatkan kesehatan remaja di Indonesia.

f) Bagi Institusi Pendidikan

Bagi instutusi pendidikan diharapkan hasil penelitian ini dapat menambah studi kepustakaan dan bermanfaat bagi mahasiswa Fakultas Kedokteran Universitas Islam Sumatera Utara.

\section{METODE PENELITIAN}

Jenis penelitian ini adalah observasional yang bersifat analitik dengan menggunakan desain cross sectional, untuk mengetahui hubungan 
status gizi dengan usia menarche pada siswi SMP Negeri 1 Kunto Darussalam Tahun 2016. Penelitian ini dilakukan padabulan April2016 sampai Desember 2016, bertempat di SMP Negeri 1 Kunto Darussalam, Jalan Hangtuah No 29, Kelurahan Kota Lama, Kecamatan Kunto Darussalam, Kabupaten Rokan Hulu, Provinsi Riau.

Dalam penelitian ini populasi adalah keseluruhan objek penelitian atau objek yang akan diteliti (Notoatmodjo, 2012). Populasi penelitian adalah siswi SMP Negeri 1 Kunto Darussalam, yang berdasarkan survei awal didapatkan jumlah populasi adalah 210 siswi. Sampel adalah objek yang diteliti dan dianggap mewakili seluruh populasi (Notoatmodjo, 2012). Untuk mengambil sampel dalam penelitian ini digunakan teknik non probability sampling dengan caraconsecutive sampling, yaitu semua subyek yang datang berurutan dan memenuhi kriteria pemilihan dimasukkan dalam penelitian sampai subyek yang diperlukan terpenuhi ${ }^{(15)}$.didapatkan sebanyak 68 orang yang memenuhi kriteria inklusi dan kriteria ekslusi.

Kriteria Inklusi :
a) Siswi SMP Negeri 1 Kunto Darussalam.
b) Siswi yang berusia 12,13 dan 14 tahun
c) Telah mengalami menarche.
d) Bersedia menjadi responden.

Kriteria Eksklusi :

a) Siswi yang berusia kurang atau lebih dari 12, 13dan 14 tahun.

b) Belum mengalami menarche .

c) Tidak bersedia menjadi responden.

Variabel Independen (Variabel Bebas) dalam penelitian ini yang menjadi variabel independennya adalah status gizi.Variabel Dependen (Variabel Terikat) dalam penelitian ini yang menjadi variabel dependennya adalah usia menarche.

Instrumen yang digunakan adalah berupa timbangan injak untuk mengukur berat badan, Microtoise untuk mengukur tinggi badan, kuesioner untuk mengetahui umur menarche responden, alat tulis dan buku tulis.
Prosedur penelitian ini dimulai setelah peneliti menerima surat izin penelitian dari KEPK Fakultas Kedokteran Universitas Islam Sumatera Utara dan telah mendapat izin Dekan Fakultas Kedokteran UISU, selanjutnya peneliti melakukan pengumpulan data. Data primer diperoleh dari hasil penelitian secara langsung terhadap siswi SMP Negeri 1 Kunto Darussalam. Data ini diambil dengan cara metode angket dan metode pengukuran langsung. Data sekunder diperoleh dari bagian Tata Usaha (TU) SMP Negeri 1 Kunto Darussalam. Data yang dibutuhkan adalah jumlah siswi dan gambar anumum SMP Negeri 1 Kunto Darussalam. Pada metode angket pengumpulan data dilakukan dengan pengisian kuesioner demografi dengan cara wawancara langsung kepada responden untuk mengidentifiksi karakteristik masing-masing responden yaitu dengan cara setelah peneliti mendapatkan responden yang sesuai dengan kriteria, peneliti menjelaskan tujuan, manfaat penelitian, prosedur penelitian dan cara pengisian kuesioner kepada responden. Selanjutnya peneliti meminta kesediaan calon responden untuk menjadi responden peneliti dengan cara menandatangani lembar persetujuan (Informed Concent). Setelah peneliti mendapatkan jumlah sampel yang sesuai dengan yang diinginkan peneliti, selanjutnya peneliti melakukan wawancara kepada responden untuk mengisi kuesioner. Dan setelah itu dilakukan pengumpulan data dengan metode pengukuran langsung yaitu dengan cara pengkuran berat badan dan tinggi badan, Metode ini dilakukan untuk mendapatkan status gizi yang berupa berat badan dengan menggunakan timbangan badan dan tinggi badan dan kemudian dimasukkan kedalam rumus Indeks Massa Tubuh (IMT).

Tehnik Pengukuran Tinggi Badan :

1. Tempelkan dengan paku microtoise pada dinding yang lurus datar setinggi tepat 2 meter. Angka 0 (nol) pada lantai yang datar rata.

2. Lepaskan sepatu atau sendal 
3. Anak harus berdiri tegak seperti sikap siap sempurna dalam baris berbaris, kaki lurus, tumit, pantat, punggung, dan kepala bagian belakang harus menempel pada dinding dan muka menghadap lurus dengan pandangan kedepan.

4. Turunkan microtoise sampai rapat pada kepala bagian atas, siku-siku harus lurus menempel pada dinding.

5. Baca angka pada skala yang nampak pada lubang dalam gulungan microtoise. Angka tersebut menunjukkan tinggi anak yang diukur $^{(12)}$.

Teknik Pengukuran Berat Badan :

1. Letakkan timbangan injak pada lantai yang datar

2. Pakaian seminim mungkin, sepatu dan barang-barang yang menambah beban dilepaskan

3. Berdiri tegap pada timbangan injak

4. Lihat angka yang tertera pada skala timbangan injak

5. Catat hasilnya dalam kilogram $(\mathrm{kg})$ (13).

Setelah melakukan penguruan tinggi badan dan berat badan pada responden, selanjutnya data yang didapatkan di masukkan kedalam rumus Indeks Massa Tubuh (IMT) untuk mengetahui status gizi dari responden.

Rumus Indeks Massa Tubuh (IMT) :

$$
\text { Berat Badan (kg) }
$$

$\overline{\text { Tinggi Badan (m) x Tinggi Badan (m) }}$

Interpretasi Hasil Pengukuran Indeks Massa Tubuh Berdasarkan WHO:

\begin{tabular}{|c|c|}
\hline KLASIFIKASI & $\begin{array}{c}\mathrm{BMI} \\
\left(\mathrm{Kg} / \mathrm{m}^{2}\right)\end{array}$ \\
\hline UNDERWEIGHT & $<18.5$ \\
\hline NORMAL WEIGHT & $18.5-24.9$ \\
\hline PRE-OBESITY & $25.0-29,9$ \\
\hline OBESITY CLASS I & $30.0-34.9$ \\
\hline
\end{tabular}

\begin{tabular}{|c|c|}
\hline OBESITY CLASS II & $35.0-39.9$ \\
\hline OBESITY CLASS III & $\geq 40$ \\
\hline
\end{tabular}

Setelah data terkumpul dilakukan pengolahan data. Pengolahan data dilakukan dengan metode SPSS (data yang dikumpulkan di tabulasi dalam bentuk distribusi frekuensi). Pengolahan data adalah suatu proses dalam memperoleh data ringkasan atau angka ringkasan dengan menggunakan caracara tertentu yaitu :

\section{Editing}

Merupakan kegiatan untuk pengecekan dan perbaikan isian formulir atau kuesioner.

2. Coding

Setelah semua kuesioner diedit atau disunting. Selanjutnya dilakukan peng "kodean" atau "coding", yakni mengubah data berbentuk kalimat atau huruf menjadi data atau angka bilangan.

\section{Data Entry}

Data, yakni jawaban - jawaban dari masing-masing responden yang dalam bentuk "kode" (angka atau huruf) dimasukkan kedalam program atau software komputer.

4. Cleaning

Apabila semua data dari setiap sumber data atau responden selesai dimasukkan, perlu dicek kembali untuk melihat kemungkinan kemungkinan adanya kesalahan kesalahan kode, ketidaklengkapan, dan sebagainya, kemudian dilakukan pembetulan atau koreksi (Notoatmodjo, 2012).

Setelah itu dilakukan analisa data yaitu analisa univariat yang bertujuan untuk menjelaskan atau mendiskripsikan karekteristik dari setiap variabel penelitian. Pada umumnya dalam analisis ini hanya menghasilkan distribusi frekuensi dan persentase dari setiap variabel. Selanjutnya dilakukan analisa bivariat yang digunakan untuk mencari hubungan antara status gizi dengan usia menarche pada siswi SMP Negeri 1 
Kunto Darussalam yaitu dengan menggunakan uji Chi-Square. Uji ChiSquare dilakukan dengan menggunakan bantuan SPSS dengan CI : 0,05 (taraf kepercayaan 95\%). Dasar pengambilan keputusan :

a. Jika nilai siq $p>0,05$ maka hipotesis penelitian ditolak.

b. Jika nilai siq $\mathrm{p}<0,05$ maka hipotesis penelitian diterima.

\section{HASIL PENELITIAN}

\section{Karekteristik Responden}

Subjek dalam penelitian ini adalah siswi SMP Negeri 1 Kunto Darussalam terdiri dari 68 siswi yang diambil dengan menggunakan tehnik non probality sampling dengan cara consecutive sampling.

Kemudian dilakukan penimbangan berat badan dan tinggi badan sehingga dapat diketahui status gizi responden dengan menggunakan rumus Indeks Massa Tubuh (IMT). Selanjutnya akan dilakukan pendataan terhadap usia menarche dari setiap masing-masing responden. Kemudian didapatkan karakteristik responden sebagai berikut :

Distribusi Frekuensi Berdasarkan Usia Responden

\begin{tabular}{ccc}
\hline Usia & Frekuensi & $\begin{array}{c}\text { Persen } \\
(\mathbf{\%})\end{array}$ \\
\hline 12 & 23 & 33.8 \\
13 & 33 & 48.5 \\
14 & 13 & 17.6 \\
\hline Total & $\mathbf{6 8}$ & $\mathbf{1 0 0}$ \\
\hline
\end{tabular}

Berdasarkan tabel distribusi frekuensi diatas dapat dilihat bahwa, responden terbanyak adalah berusia 13 tahun yaitu sebanyak 33 orang (48.5\%), sedangkan responden yang berusia 12 tahun yaitu sebanyak 23 orang (33.8\%) dan yang berusia 14 tahun sebanyak 13 orang $(17.6 \%)$
Distribusi Frekuensi Berdasarkan Usia Menarche Responden

\begin{tabular}{ccc}
\hline $\begin{array}{c}\text { Usia } \\
\text { Menarche }\end{array}$ & Frekuensi & $\begin{array}{c}\text { Persen } \\
(\mathbf{\%})\end{array}$ \\
\hline 10 & 7 & 10.3 \\
11 & 20 & 29.4 \\
12 & 32 & 47.1 \\
13 & 7 & 10.3 \\
14 & 2 & 2.9 \\
\hline Total & $\mathbf{6 8}$ & $\mathbf{1 0 0}$ \\
\hline \multicolumn{2}{c}{ Berdasarkan }
\end{tabular}

frekuensi diatas dapat dilihat bahwa, usia menarche responden terbanyak adalah 12 tahun yaitu sebanyak 32 orang (47.1\%), sedangkan responden yang mendapatkan usia menarche pada usia 10 tahun yaitu sebanyak 7 orang (10.3\%), pada usia 11 tahun yaitu sebanyak 20 orang (29.4\%), pada usia 13 tahun yaitu sebanyak 7 orang (10.3\%) dan pada usia 14 tahun yaitu sebanyak 2 orang (2.9\%).

Distribusi Frekuensi Berdasarkan Status Gizi Responden

\begin{tabular}{lcc}
\hline Status Gizi & Frekuensi & $\begin{array}{c}\text { Persen } \\
(\mathbf{\%})\end{array}$ \\
\hline Underweight & 8 & 11.8 \\
Normalweight & 42 & 61.8 \\
Pre-Obesity & 14 & 20.6 \\
Obesity & 4 & 5.9 \\
\hline \multicolumn{2}{c}{ Total } \\
\hline
\end{tabular}

2. Hasil Analisa Data

Distribusi Responden Berdasarkan Status Gizi dengan Usia Menarche 


\begin{tabular}{ccc}
\hline Status Gizi & Frekuensi & $\begin{array}{c}\text { Usia } \\
\text { Menarche }\end{array}$ \\
\hline Underweight & 8 & 12.13 \\
Normalweight & 42 & 11.79 \\
Pre-Obesity & 14 & 11.43 \\
Obesity & 4 & 10.25 \\
\hline Total & $\mathbf{6 8}$ & $\mathbf{1 1 . 6 6}$ \\
\hline
\end{tabular}

dengan usia menarche, dimana terjadi pola penurunan rata-rata usia menarche seiring dengan peningkatan status gizi. Didapatkan usia menarche rata-rata pada siswi yang obesitas adalah paling awal dibanding kelompok yang lain yaitu pada usia 10.25 tahun.

Untuk menilai hubungan antara status gizi dengan usia menarche pada siswi SMP Negeri 1 Kunto Darussalam Tahun 2016 akan digunakan uji ChiSquare.

Berdasarkan tabel diatas, didapatkan hubungan timbal balik antara status gizi

Hubungan Status Gizi dengan Usia Menarche Pada Siswi SMP Negeri 1 Kunto Darussalam

\begin{tabular}{|c|c|c|c|c|c|c|c|}
\hline \multirow{2}{*}{ Status Gizi } & \multicolumn{5}{|c|}{ Usia Menarche } & \multirow{2}{*}{ Total } & \multirow{2}{*}{$\begin{array}{c}P \\
\text { value }\end{array}$} \\
\hline & 10 & 11 & 12 & 13 & 14 & & \\
\hline Underweight & 0 & 1 & 5 & 2 & 0 & 8 & \multirow{8}{*}{0.013} \\
\hline$\%$ & $0 \%$ & $12.5 \%$ & $62.5 \%$ & $25.0 \%$ & $0.0 \%$ & $100 \%$ & \\
\hline Normalweight & 2 & 13 & 21 & 4 & 2 & 42 & \\
\hline$\%$ & $4.8 \%$ & $31.0 \%$ & $50.0 \%$ & $9.5 \%$ & $4.8 \%$ & $100 \%$ & \\
\hline Pre-Obesity & 2 & 5 & 6 & 1 & 0 & 14 & \\
\hline$\%$ & $14.3 \%$ & $35.7 \%$ & $42.9 \%$ & $7.1 \%$ & $0.0 \%$ & $100 \%$ & \\
\hline Obesity & 3 & 1 & 0 & 0 & 0 & 4 & \\
\hline$\%$ & $75.0 \%$ & $25.0 \%$ & $0.0 \%$ & $0.0 \%$ & $0.0 \%$ & $100 \%$ & \\
\hline Total & 7 & 20 & 32 & 7 & 2 & 68 & \\
\hline$\%$ & $10.3 \%$ & $29.4 \%$ & $47.1 \%$ & $10.3 \%$ & $2.9 \%$ & $100 \%$ & \\
\hline \multicolumn{4}{|c|}{$\begin{array}{l}\text { Siswi yang menarche pada usia } \\
11 \text { tahun dengan status gizi underweight } \\
\text { sebanyak } 1 \text { orang }(12.5 \%) \text {, dengan status } \\
\text { gizi normalweight sebanyak } 13 \text { orang } \\
(31 \%) \text {, dengan status gizi pre-obesity } \\
\text { sebanyak } 5 \text { orang }(35.7 \%) \text {, dan dengan } \\
\text { status gizi obesity sebanyak } 1 \text { orang } \\
(25.0 \%) \text {. } \\
\text { Siswi yang menarche pada usia } \\
12 \text { tahun dengan status gizi underweight } \\
\text { sebanyak } 5 \text { orang ( } 62.5 \%) \text {, dengan status } \\
\text { gizi normalweight sebanyak } 21 \text { orang }\end{array}$} & \multicolumn{4}{|c|}{$\begin{array}{l}\text { Siswi yang menarche pada usia } \\
14 \text { tahun dengan status gizi underweight } \\
\text { tidak ada }(0 \%) \text {, dengan status gizi } \\
\text { normalweight sebanyak } 2 \text { orang }(4.8 \%) \text {, } \\
\text { dengan status gizi pre-obesity tidak ada } \\
(0 \%) \text {, dan dengan status gizi obesity tidak } \\
\text { ada }(0 \%) \text {. } \\
\text { Berdasarkan hasil analisa } \\
\text { menggunakan uji Chi-Square di peroleh } \\
\text { nilai } p \text {-value }=0,013(\mathrm{p}<\alpha(0,05)) \text {. Maka } \\
\text { hipotesis nol dalam penelitian ini ditolak, } \\
\text { yang berarti bahwa terdapat hubungan }\end{array}$} \\
\hline
\end{tabular}


antara status gizi dengan usia menarche pada siswi SMP Negeri 1 Kunto Darussalam.

\section{PEMBAHASAN}

Menstruasi didefenisikan sebagai suatu kondisi dimana terjadi perubahan karakteristik seseorang yang merupakan salah satu tanda bahwa seseorang anak telah memasuki masa pubertas. Berbagai penelitian telah dilakukan untuk mengetahui faktor-faktor penyebab terjadinya peningkatan usia menarche ini. Beberapa diantara faktor penyebab tersebut adalah status gizi dan faktorfaktor lainnya. Dengan mengetahui faktorfaktor penyebab yang berperan terhadap timbulnya menarche dini pada anak, maka akan dapat dilakukan pencegahan pada individu resiko tinggi.

Penelitian ini dilakukan pada 68 siswi SMP Negeri 1 Kunto Darussalam Riau. Penelitian dilakukan dengan mengambil data primer melalui kuesioner dan pengukuran berat badan dan tinggi badan secara langsung kepada siswi SMP Negeri 1 Kunto Darussalam.

Dari hasil perhitungan statistik dengan menggunakan Chi-Square, dengan tingkat kepercayaan $95 \%$ didapatkan nilai $\mathrm{p}<\alpha$. Dapat disimpulkan bahwa hipotesis nol ditolak, hal ini menunjukkan terdapat hubungan antara status gizi dengan usia menarche pada siswi SMP Negeri 1 Kunto Darussalam. Hal ini sesuai dengan beberapa penelitian salah satunya penelitian yang dilakukan oleh Astika (2012) yang dilakukan di SMP Negeri 3 Medan, menunjukkan adanya hubungan status gizi dengan kejadian menarche dini. Sama halnya dengan penelitian yang dilakukan Amallia (2012) yang dilakukan pada Siswi Sekolah Dasar Ngoresan Surakarta didapatkan hubungan Indeks Massa Tubuh dengan usia menarche.

Dari hasil penelitian didapatkan ratarata usia menarche pada siswi SMP negeri 1 Kunto Darussalam yaitu 11.66 tahun, ini menandakan terjadinya penurunan usia menarche, dimana rata-rata usia menarche normal yaitu 13 tahun. Hal ini disebabkan semakin membaiknya status gizi pada siswi SMP Negeri 1 Kunto Darussalam. Dimana didapatkan rata-rata status gizi pada siswi SMP Negeri 1 Kunto
Darussalam adalah Normalweight. Salah satu yang mempengaruhi membaiknya status gizi pada siswi SMP Negeri 1 Kunto Darussalam yaitu dikarenakan ratarata siswi SMP Negeri 1 Kunto Darussalam berdomisili dipusat kota dan memiliki perekonomian yang baik.

Dari hasil penelitian menunjukkan adanya perbedaan usia terjadinya menarche antara siswi dengan status gizi Underweight, Normalweight, Pre-Obesity dan Obesity. Dimana didapatkan kelompok siswi yang mempunyai status gizi Obesity rata-rata usia menarche ialah 10.25 tahun, yaitu lebih awal dibandingkan dengan usia rata-rata menarche kelompok siswi status gizi Underweight, Normalweight dan PreObesity. Hal ini disebabkan, siswi dengan status gizi Obesity memiliki konsentrasi kolesterol tinggi, ini menyebabkan makin tingginya hormon androgen sebagai bahan aromatisasi dalam jaringan lemak. Hormon androgen diubah menjadi estrogen, sehingga mempengaruhi percepatan kematangan reproduksi. Oleh sebab itu siswi Obesity relatif mencapai usia menarche lebih dini.

Hal yang mempengaruhi Obesity pada siswi SMP Negeri 1 Kunto Darussalam ini diakibatkan oleh kurang sehatnya makanan yang dikonsumsi, dimana siswi banyak mengkonsumsi makanan tinggi akan kadar kolesterol, seperti makan makanan Fast Food yang kaya lemak, banyaknya ditemui makanan yang berminyak dikantin sekolah dan kurangnya pola hidup sehat, seperti jarang berolah raga.

Menurunnya usia menarche ini akan memiliki dampak terhadap kesehatan, seperti insidensi kardiovaskular yang lebih tinggi, termasuk kanker terutama kanker payudara. Selain itu, menarche dini berhubungan dengan gejala kecemasan, depresi, hubungan seks prematur dan prilaku kekerasan.

Namun demikian perlu dipahami bahwa status gizi bukanlah satu-satunya faktor yang mempengaruhi usia menarche. Beberapa faktor yang lain perlu dipertimbangkan dalam upaya prevensi terhadap masalah yang akan muncul dikemudian hari. 


\section{KESIMPULAN}

Berdasarkan hasil dan analisa data penelitian yang telah diperoleh terhadap 68 siswi SMP Negeri 1 Kunto Darussalam Tahun 2016, adapun kesimpulan yang dapat diambil dalam penelitian ini adalah sebagai berikut :

a. Berdasarkan usia menarche, siswi paling banyak mendapat menstruasi pertama kali saat usia 12 tahun yaitu sebanyak 32 orang $(47.1 \%)$,

b. Berdasarkan status gizi, siswi paling banyak dengan status gizi baik (Normalweight) yaitu sebanyak 42 orang $(61.8 \%)$.

c. Usia menarche rata-rata pada siswi SMP Negeri 1 Kunto Darussalam yaitu 11.66 tahun.

d. Terdapat hubungan antara status gizi dengan usia menarche pada siswi SMP Negeri 1 Kunto Darussalam Tahun 2016.

\section{SARAN}

Berdasarkan proses penelitian yang telah dijalankan oleh peneliti dalam menyelesaikan penelitian ini maka dapat rekomendasikan beberapa saran yang mungkin bermanfaat bagi semua pihak yang berperan dalam penelitian ini yaitu:

a. Bagi pihak sekolah dan guru, dapat membuat program tentang kesehatan reproduksi remaja dan penyuluhan tentang pendidikan sex dalam upaya meningkatkan kesehatan remaja.

b. Bagi petugas kesehatan, dapat dilakukan penyuluhan tentang kesehatan reproduksi remaja dan melakukan observasi tentang usia menarche dan status gizi remaja dari tahun pertahun berikutan dengan berlakunya perubahan gaya hidup dari masa kemasa.

c. Bagi responden, seharusnya menjalani gaya hidup yang lebih sehat dalam upaya mencegah terjadinya obesitas dengan cara melakukan gaya hidup dan pola hidup yang sehat dalam kehidupan sehari-hari, seperti mengkonsumsi makanan sesuai kebutuhan dan tidak berlebihan, serta menghindari makanan yang berlemak karena dapat mengakibatkan obesitas. d. Bagi pihak orang tua, dengan anak yang sudah mengalami menarche disarankan untuk memberikan pelajaran, pengetahuan dan pendidikan tentang sex kepada anak, untuk menghindari terjadinya sex bebas. Dan di sarankan juga kepada orang tua dengan anak yang belum memasuki masa pubertas, untuk lebih memperhatikan gizi anak, dengan memberikan gizi yang cukup dan seimbang, sehingga dicapainya kesehatan reproduksi yang normal.

e. Bagi peneliti yang ingin melakukan penelitian dimasa yang akan datang, dapat dilakukan dengan populasi yang lebih besar dan menyeluruh serta melakukan pertanyaan yang lebih mendalam seperti riwayat usia menarche awal dalam keluarga dan juga mengidentifikasi faktor-faktor lain yang turut mempengaruhi usia menarche. Selain itu, peneliti juga dapat meneliti lebih lanjut tentang obesitas yang semakin meningkat dikalangan remaja.

\section{DAFTAR PUSTAKA}

Agria, I., Ruri,N.S., Ircham., (2012). Gizi Reproduksi. Yogyakarta : Penerbit Fitramaya: 132-136.

Aishah, S., (2011). Karya Tulis Ilmiah Hubungan Antara Status Gizi dengan Usia Menarche pada Siswa Sekolah Dasar (SD) dan Sekolah Menengah Pertama (SMP) Shafiyyatul Amaliyyah Medan Tahun 2011. Medan : Fakultas Kedokteran Universitas Sumatera Utara.

Arisman. (2010). Gizi dalam Daur Kehidupan. Ed 2. Jakarta : Penerbit Buku Kedokteran EGC: 76-100.

Banudi, L.A., (2013). Gizi Kesehatan Reproduksi. Jakarta : Penerbit Buku Kedokteran EGC: 89-105.

Edward, et al., (2007). Mean Age of Menarche in Trinidad and Its Relationship to Body Mass Index, Ethinicity and Mothers Age of Menache. Anatomy Unit, Faculty of Medical Sciences University of the West Indies. OnLine Journal of Biological Sciences 7 (2): 66-71. 
Gant, N.F., Gary, C., (2011). DasarDasar Ginekologi \& Obstetri. Jakarta : Penerbit Buku Kedokteran EGC: 2-9

Karapanou, O., and Papadimitriou,A., 2010. Determinan of menarche. Reproductive Biology and Endocrinology 8(115). Available from http://www.rbej.com/content/8/1/11 5. [Accesed 23 Mei 2016].

Noerpramana, N.P., (2011). Perempuan dalam Berbagai Masa Kehidupan In: Mochamad, A., Ali, B., Prajitno, P., ed. Ilmu Kandungan. Ed 3. Jakarta : Bina Pustaka Sarwono Prawiriharjo: 92- 110.

Notoatmodjo, S., (2012). Metodologi Penelitian Kesehatan. Ed rev. Jakarta : Rineka Cipta.

Proverawati, A., Siti, M., (2014). Menarche. Yogyakarta : Nuha Medika: 58-78.

Sarwono, S.W., (2011). Psikologi Remaja. Ed rev. Jakarta : Rajawali Pers: 171-245.

Soetjiningsih., (2015). Tumbuh Kembang Remaja In: Soetjiningsih., Gde, R., ed. Tumbuh Kembang Anak. Ed 2. Jakarta : Penerbit Buku Kedokteran EGC: 116-130.

Soetjiningsih., (2015). Tumbuh Kembang Remaja In: Soetjiningsih., Gde, R., ed. Tumbuh Kembang Anak. Ed 2. Jakarta : Penerbit Buku Kedokteran EGC: 116-130.

Silvia, H.N., (2015). Pengukuran Antropometri. Available from : http://physiosilvia.com/ pengukuran-antropometri/ [Accesed 4 Juni 2016].

Supariasa, I.D.N., Bachyar, B., Ibnu, F., (2012). Penilaian Status Gizi. Ed rev. Jakarta : Penerbit Buku Kedokteran EGC: 17-86. 